\title{
Cornelia de Lange syndrome in several members of the same family
}

\author{
D KUMAR*, CE BLANK*, ANDBLGRIFFITHS \\ From * the Centre for Human Genetics, 117 Manchester Road, Sheffield; and + Neath General Hospital, \\ Neath, Glamorgan.
}

SUMmARY A family is reported in which several members have the Cornelia de Lange syndrome and other members show facial dysmorphism and other features reminiscent of this syndrome. The segregation pattern is consistent with the view that the dysmorphic features (variable) are the manifestation of a single gene in heterozygous form. Chromosome abnormality was not found.

In 1933 Cornelia de Lange, a distinguished Dutch paediatrician, described two unrelated infant girls' with a syndrome characterised by mental retardation and physical anomalies involving face and limbs. ${ }^{1}$ Brachmann had reported a similar condition from Amsterdam in $1916 .{ }^{2}$ Opitz et al ${ }^{3}$ suggested the syndrome be designated the Brachmann-de Lange syndrome. It is also known as 'Amsterdam dwarfism'. Reports have appeared from various parts of the world and in 1970 about 250 examples were on record. ${ }^{4}$ The aetiology of this dysmorphic syndrome is not clear. Although it is familial the condition has not been shown to have a characteristic pedigree pattern.

The cardinal features of the Cornelia de Lange syndrome $^{5}$ are short stature, mental retardation, microbrachycephaly, bushy eyebrows, synophrys, long curly eye lashes, small nose, anteverted nostrils, characteristic lips and mouth, high arched palate, micrognathia, hirsutism, and small hands and feet with brachydactyly. About $20 \%$ of patients have seizures. IQ varies from 40 to 85 . Occasional anomalies are myopia, microcornea, astigmatism, optic atrophy, coloboma of the optic nerve, strabismus, proptosis, choanal atresia, low set ears, cleft palate, congenital heart defect (most commonly ventricular septal defect), hiatus hernia, pyloric stenosis, brachyoesophagus, and undescended testes. Dermatoglyphic findings include absence of the second or third or both interdigital triradii on the hands.

We report a family in which several members have been recognised to have the Cornelia de Lange syndrome and other members have an odd facial appearance and other features reminiscent of this syndrome.

Received for publication 6 September 1984 Accepted for publication 12 October 1984.

\section{Family history and case reports}

The consultand (fig 1, III.27), aged 24 years, was referred to the Centre for Human Genetics, Sheffield, for genetic counselling because her brother (III.26) had been diagnosed as having the features of the Cornelia de Lange syndrome. Her mother (II.7) had had five children. The first male infant (III.28), born at 36 weeks' gestation and who died in the neonatal period, had a large head, odd facies, and abnormal feet. The significance of these abnormalities to the diagnosis of Cornelia de Lange syndrome is unclear. Another male infant (III.30), who died at $31 / 2$ months of age due to respiratory illness associated with a heart defect, had been designated an example of the Cornelia de Lange syndrome by a different paediatrician from that examining III.26. There was no consanguinity in either marriage. Both her husbands were phenotypically normal. The mother (II.7) has features consistent with the diagnosis of the Cornelia de Lange syndrome. Her two daughters (III.27 and III.29) are without significant stigmata. One of her sisters (II.5) is reported to have a strong facial resemblance to her and to be of short stature and of low intelligence. That sister has had a number of pregnancies but only four daughters are alive. Two of them (III.19 and III.25) are reported to be mentally retarded with an abnormal facial appearance. One of them (III.25) had been diagnosed by one of the authors (BLG), without knowledge of previous assessments, as having the Cornelia de Lange syndrome. She is one of twins and the other twin was a macerated stillbirth. A sixth pregnancy resulted in a stillbirth (III.20) and a seventh in an early neonatal death (III.21). Both these babies were reported to have had a similar facial appearance to III.25. II.1 is reported to have had a 


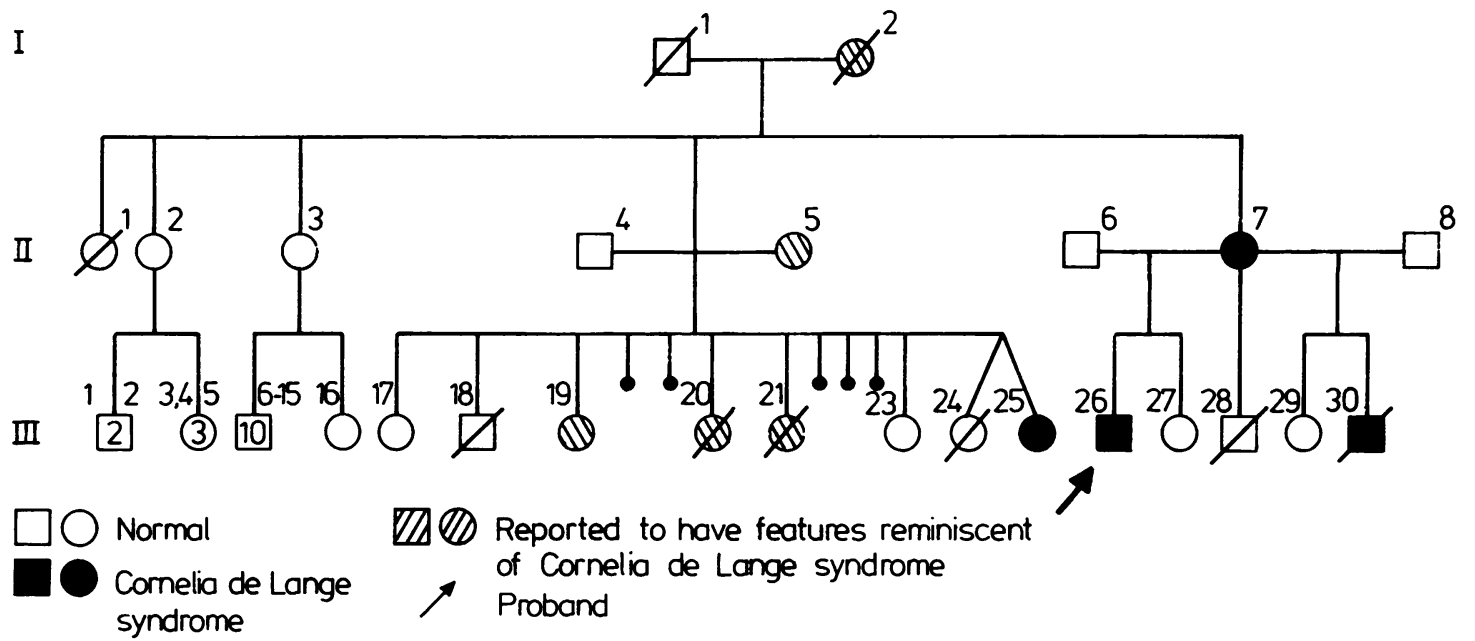

FIG 1 Pedigree showing the affected and possibly affected subjects with the Cornelia de Lange syndrome.

congenital heart defect although she died aged 55 years. II. 2 and II. 3 are said to be normal with a number of healthy offspring (III.1 to 16). The grandmother (I.2) was also reported to be of short stature with odd facial features, short and stubby fingers, and small feet with webbed toes.

\section{Case reports}

The proband (III.26, fig 2), aged 28 years, was born on 27.8.57 following a normal delivery after a 41 week gestation. The birth weight was $2750 \mathrm{~g}$. Physical examination revealed a small male infant with peculiar facies. At 18 months of age he had a strangulated hernia which required surgical treatment. A diagnosis of the Cornelia de Lange syndrome was made in 1963 . His general health has been good, apart from occasional respiratory infections. The right testicle has never been palpable. The left required surgical placement in the scrotum. He had faecal incontinence up to the age of 5 years. His growth has been generally slow; his weight at 6 months was $5 \cdot 2 \mathrm{~kg}$ and at 1 year just over $6 \mathrm{~kg}$, with a crown-heel length of $66 \mathrm{~cm}$ (below the 3rd centile) and a head circumference of $43 \mathrm{~cm}$ (below the $3 \mathrm{rd}$ centile). The bone age at 5 years 3 months was
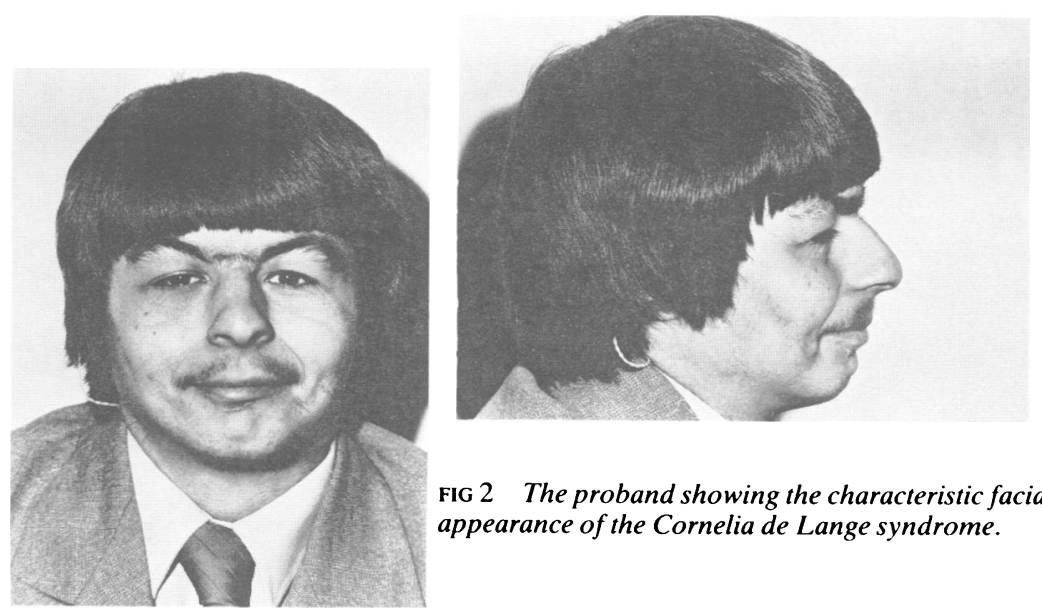

FIG 2 The proband showing the characteristic facial appearance of the Cornelia de Lange syndrome. 


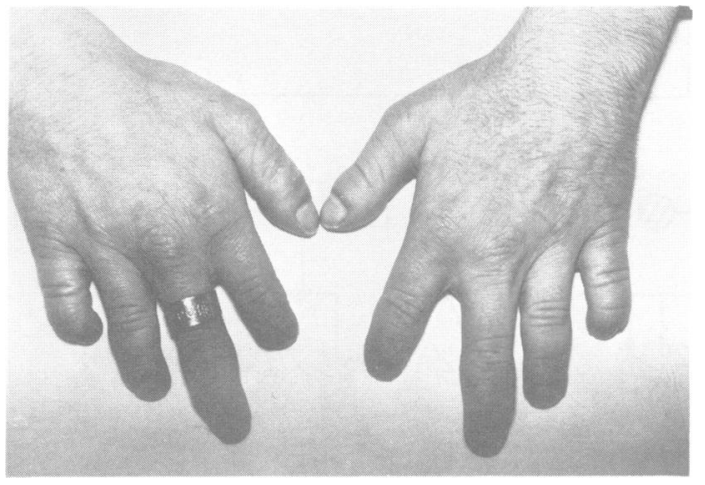

FIG 3 Small hands, short stubby fingers, and clinodactyly of the fifth finger of the proband.

estimated to be at 41 months. His height at 13 years was $122 \mathrm{~cm}$ and weight $22 \mathrm{~kg}$. His development has been retarded in all directions. An intelligence assessment at 5 years 5 months (Terman-Merril scale) gave an IQ of 43 and at 6 years 11 months 36 . $\mathrm{He}$ now attends a training centre. He has bilateral intermittent deafness.

At 25 years of age, physical examination revealed a small man who appeared to be mentally subnormal with hirsutism. The eyebrows (fig 2 ) were confluent in the centre of the forehead forming a triangular shaped area. An antimongoloid slant was quite marked and the eyelashes were long and abundant.

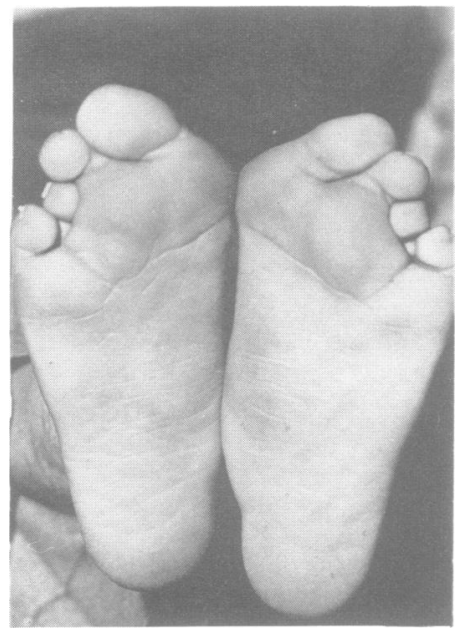

FIG 4 Proband's feet showing forefoot abduction, hallux valgus, and overriding third and fourth toes.
The frontal hair line was encroaching the forehead, which was small. The nose was long and beaky and $\stackrel{5}{9}$ the upper lip was thin and down-turned with a long philtrum. The palate was high arched and there was $\frac{\overline{\bar{O}}}{\mathrm{n}}$ marked micrognathia. The ears were large, mal- $\frac{\bar{\sigma}}{\overrightarrow{0}}$

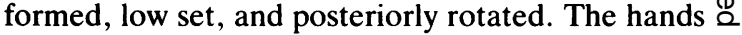
were small, the palms were square, and the fingers were short and stubby (fig 3). There was clino- $\vec{\circ}$ dactyly of the little fingers of both hands. Both feet showed forefoot abduction, hallux valgus, and $\vec{\omega}$ overriding third and fourth toes (fig 4). The neck was 9 short, with a low posterior hair line. However, there was no radiological evidence of any cervical spine anomaly. The genitalia were not fully developed and $N$ only the left testicle could be felt, high up in the scrotum. Dermatoglyphs did not show any abnormal $\mathscr{Q}$ pattern. Cytogenetic studies (prometaphase band- o ing) confirmed a normal male chromosome complement.

The mother (II.7) of the proband was also examined by one of the authors (DK). She was short $\frac{c}{0}$ statured (height $151 \mathrm{~cm}$ ) with small hands and short $\overrightarrow{0}$ stubby fingers. She had facial features consistent $\stackrel{\circ}{\infty}$ with the diagnosis of the Cornelia de Lange syn- or drome, but she appeared to be mentally normal. Dermatoglyphs were not unusual. Cytogenetic studies revealed a normal female chromosome complement. One of the cousins of the proband (III.25) was examined by one of the authors (BLG). She was $\stackrel{\mathbb{Q}}{\complement}$ born on 22.2 .72 and weighed $1.5 \mathrm{~kg}$ at birth which $\overrightarrow{\vec{\theta}}$ was at 30 to 32 weeks' gestation. She had a stormy 을 neonatal period and was very slow to take feeds. She progressed very slowly and remained in the neonatal nursery up to the age of 6 months. Her subsequent development was very slow. Her physical growth has been markedly retarded (height and weight $\overline{7}$ below the 3 rd centile). She showed the characteristic $\stackrel{3}{\text {. }}$. facies of Cornelia de Lange syndrome (fig 5) with

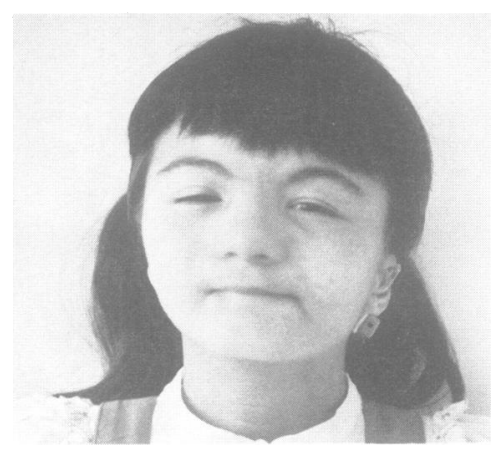

FIG 5 Characteristic facial appearance of III.25. 


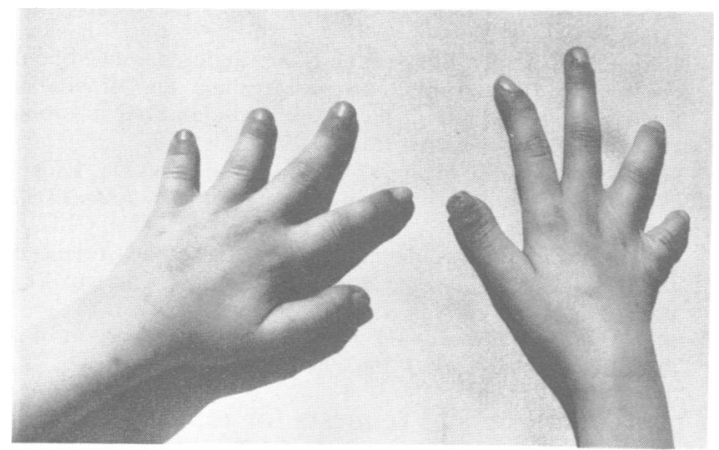

FIG 6 Small hands and short stubby fingers of III.25.

small hands and feet (fig 6). She was severely deaf and wore a hearing aid. She was only able to communicate by means of very basic speech but, however, she could communicate well using the

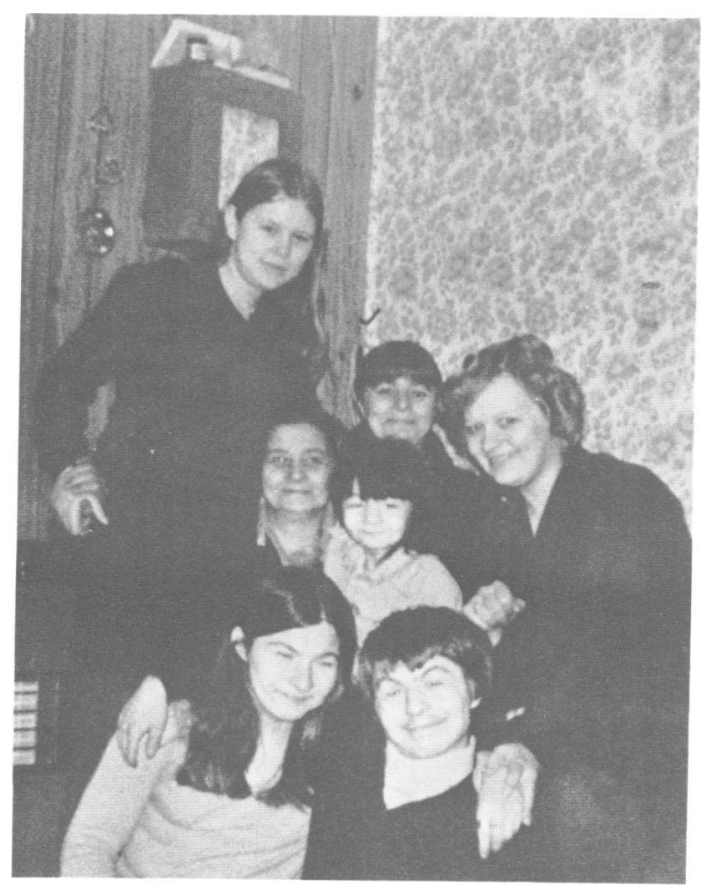

FIG 7 Family photograph. From top left: normal sister of the proband (III.29), mother (II.7) with facial features of the Cornelia de Lange syndrome, and the consultand (III.27). In the middle from left: aunt (II.5), showing facial resemblance to the mother, and her daughter (III.25) with a similar facial appearance. From bottom left: cousin (III.19) with similar facial appearance to the proband (III. 26).
Makaton sign language. Her learning age at 11 years 7 months was 8 years and the Vineland Social Maturity Scale gave her a social age of $5 \cdot 5$ years. She now attends a partial hearing unit in the school. Cytogenetic studies on III. 25 revealed a normal female chromosome complement. A family photograph is shown in fig 7 .

\section{Discussion}

Many aspects of the Cornelia de Lange syndrome have been recognised since the original description by de Lange in $1933,{ }^{1}$ but familial cases are very few and no clear pedigree pattern is evident. Although chromosome irregularity has been observed, ${ }^{6}$ abnormality is inconsistent and probably coincidental. ${ }^{7}$ Similar clinical features have been observed in children with partial trisomy $3 q(3 q 21 \rightarrow q$ ter $)$ and compared with those having the Cornelia de Lange syndrome. ${ }^{\times}$Heterogeneity of origin seems a likely possibility. There is no previous recorded case of a patient with clear cut Cornelia de Lange syndrome having an affected child, although Borghi et al ${ }^{9}$ and Beer et al ${ }^{10}$ reported families in which a parent of an affected child is said to have had minor manifestations. It must, however, be recalled that the physical and mental limitations imposed upon these patients by the condition make reproduction unlikely. ${ }^{4}$ Borghi et $a t^{9}$ suggested dominant inheritance and Opitz ${ }^{11}$ thought the condition to be 'incompletely recessive'. Autosomal dominant inheritance is also discussed by McArthur and Edwards. ${ }^{12}$ Although only three abnormal persons in the family described in this report were actually examined by the present authors, the clinical features exhibited fit the Cornelia de Lange syndrome well. A half brother of the proband was independently designated as an example of this condition. His grandmother and one maternal aunt have stigmata reminiscent of this syndrome. It is reasonable to suggest that the features observed in all these affected persons are manifestations of the same genetic defect. This condition is clearly segregating in this family as a dominant trait with variable expression.

The authors thank Mrs Edna Maltby, Senior Scientific Officer, for performing the cytogenetic studies. We are grateful to the Department of Medical Illustration, Royal Hallamshire Hospital, Sheffield, for the photographs. This paper could not have been completed without the generous cooperation of the family members. 


\section{References}

1 De Lange C. Sur un type nouveau de degeneration (typus amsteldoamensis). Arch Med Enf 1933;36:713-9.

2 Bishun NP, Morton WRM. Brachmann-de Lange syndrome. Lancet 1965 ; i:439.

3 Opitz JM, Segal AT, Lehrke R, Nadler H. Brachmann-de Lange syndrome. Lancet 1964;ii:1019.

${ }^{4}$ Berg JM, McCreary BD, Ridler MAC, Smith GF. The de Lange syndrome. Oxford: Pergamon Press, 1970.

5 Smith DW. Recognizable patterns of human malformation. 3rd ed. Philadelphia: Saunders, 1982:76-7.

6 Broholm KA, Eeg-Olofsson O, Hall B. An inherited chromosome aberration in a girl with signs of de Lange syndrome. Acta Paediatr Scand 1968;57:547-52.

${ }^{7}$ Beratis NG, Hsu LYF, Hirschhorn K. Familial de Lange syndrome: report of three cases in a sibship. Clin Genet 1971;2:170-6.

${ }^{8}$ Borgaonkar DS, ed. 3q partial trisomy syndrome. In: Chromo- somal variation in man. 3rd ed, appendix 11/651. New York: Alan R Liss, 1977.

9 Borghi A, Glusti G, Biogozzi U. Nanismo degenerative tipo di Amsterdam (typus amstelodamensis-malatia di Cornelia de Lange). Prezentazione di un caso e considerazioni di ordine genetico. Acta Genet Med (Roma) 1954;3:365-72.

10 Beer S, Wallis K, Czerniak P. Two cases of De Lange's syndrome (typus amstelodamensis degenerativus). J Ment Defic Res 1968;12:128-37.

11 Opitz JM. Editorial comments on the etiology of the Cornelia de Lange syndrome. In: Year Book of Pediatrics. Chicago: Year Book Medical Publishers, 1964-1965 series: 499-504.

12 McArthur RG, Edwards JH. De Lange syndrome: report of 20 cases. Can Med Assoc J 1967;96:1185-98.

Correspondence and requests for reprints to Dr $D^{c}$ Kumar, Centre for Human Genetics, 117 Manches- N ter Road, Sheffield S10 5DN. 